\title{
Controle da qualidade higiênico-sanitária na recepção e no armazenamento de alimentos: um estudo em escolas públicas municipais de Salvador, Bahia
}

\author{
Valteneide Bitencourt da Silva ${ }^{1}$ e Ryzia de Cássia Vieira Cardoso ${ }^{2}$
}

Trata-se de um estudo de caso com abordagem qualitativa e quantitativa, cujo objetivo foi caracterizar o controle da qualidade higiênico-sanitária na recepção e no armazenamento de alimentos em três escolas da Coordenadoria Regional de Ensino de Pirajá, Salvador (Bahia). Para a coleta de dados foram utilizados: lista de verificação; entrevistas semi-estruturadas com diretores escolares, merendeiras e secretária escolar; observação participante e análise documental. Adotou-se a análise descritiva para avaliação dos dados da lista de verificação, e foram definidos 5 grupos de classificação para as escolas - crítico, insatisfatório, regular, bom e excelente, de acordo com o percentual de adequação às legislações sanitárias vigentes. Todas as escolas foram classificadas em nível de atendimento insatisfatório, e os aspectos relativos às etapas de recepção dos alimentos e armazenamento de hortifrutigranjeiros foram os que mais contribuíram para o baixo nível de adequação global nas mesmas. Na perspectiva qualitativa, os discursos estavam em conformidade com as deficiências identificadas durante a observação participante e aplicação da lista de verificação. O desperdício de alimentos foi uma das principais implicações da falta de controle de qualidade nas etapas avaliadas. Os resultados evidenciam a necessidade de ações corretivas, que visem à promoção dos objetivos do Programa Nacional de Alimentação Escolar.

Palavras-chave: alimentação escolar, controle de qualidade, armazenamento de alimentos, higiene dos alimentos.

\section{Quality control for food safety in handling and storage: a study of public schools in Salvador, Bahia}

This case study uses a qualitative and quantitative approach aiming to evaluate the hygienic and sanitary quality control for the handling and storage of food at three public schools in the Pirajá Regional School District in Salvador, Bahia. For data collection we used a checklist; semi-structured interviews of school principals, cooks and staff; active observation and document analysis. A descriptive analysis was adopted to evaluate the checklist data, from which five classifications were defined: critical, unsatisfactory, regular, good and excellent, according to compliance with current sanitary regulation. All schools displayed unsatisfactory levels of service, and the stages of food handling and storage of produce being those contributing the most to the low level of the schools' performance. From a qualitative perspective, discussions were in accordance with the deficiencies identified during the active observation and checklist application. Excessive waste of food was the main consequence from the lack of quality control in the evaluated steps. These results show the need for corrective actions that aim at promoting the objectives of the National School Lunch Program.

Key-words: school lunch, quality control, food storage, food safety.

\footnotetext{
1 Nutricionista, Especialização em Gestão da Alimentação Escolar sob a forma de Residência, Escola de Nutrição, Universidade Federal da Bahia (UFBA). Correspondência: Rua São José, 47-E, Engomadeira, CEP 41200-350, Salvador, BA. E-mail: valteneide@hotmail.com.

${ }^{2}$ Profa. Dra. em Ciência e Tecnologia de Alimentos. Departamento de Ciência dos Alimentos, Escola de Nutrição, Universidade Federal da Bahia (UFBA).
} 


\section{INTRODUÇÃO}

O Programa Nacional de Alimentação Escolar (PNAE) é considerado um dos maiores programas na área de alimentação escolar no mundo e o único com atendimento universalizado ${ }^{[1]}$. Tem por objetivo contribuir para o crescimento e o desenvolvimento biopsicossocial, a aprendizagem, o rendimento escolar e a formação de práticas alimentares saudáveis dos alunos, por meio de ações de educação alimentar e nutricional e da oferta de refeições que cubram as suas necessidades nutricionais, durante a permanência na escola. Dentre as diretrizes do PNAE, destaca-se o emprego da alimentação saudável e adequada, compreendendo o uso de alimentos variados, seguros, que respeitem a cultura, tradições e hábitos alimentares saudáveis [2].

Segundo a Food and Agriculture Organization of the United Nations/World Health Organization (FAO/WHO) [3] segurança de alimentos é a garantia de que $O$ consumo de um determinado alimento não cause dano ao consumidor, quando preparado ou consumido de acordo com o seu uso intencional. $\mathrm{O}$ alimento deve, portanto, ser inócuo à saúde, ou seja, estar livre de contaminantes químicos, físicos e microbiológicos. $\mathrm{O}$ consumidor, por sua vez, deve ser capaz de exigir a qualidade microbiológica, sensorial e nutricional do alimento que adquire.

Com relação à qualidade alimentar, Azevedo [4] afirma que se trata de um termo muito vasto e inclui uma série de critérios que têm base especialmente na garantia do valor nutricional e na inocuidade do alimento frente aos agentes biológicos. Segundo a autora, o investimento na qualidade da alimentação escolar é uma forma de garantir o desenvolvimento e a manutenção da saúde das crianças, visto que, para algumas famílias, as refeições na escola são a única fonte alimentar das crianças durante o dia e preocuparse com a qualidade dessa alimentação é um dos aspectos determinantes para uma vida futura saudável.

A Resolução do Fundo Nacional de Desenvolvimento da Educação (FNDE), no $38 / 2009$ [5], contempla normas relativas ao controle de qualidade da alimentação escolar, desde a aquisição dos gêneros até o consumo das refeições pelos alunos. Conforme o Art. 25, $\S 10$, os produtos a serem adquiridos para a clientela do PNAE deverão atender ao disposto na legislação de alimentos, estabelecida pela Agência Nacional de Vigilância Sanitária (ANVISA)/Ministério da Saúde (MS) e pelo Ministério da Agricultura
Pecuária e Abastecimento (MAPA) e atribui às Entidades Executoras (EE), Unidades Executoras (UEx) e escolas de educação básica a responsabilidade pela garantia dessa qualidade. $O$ Conselho de Alimentação Escolar (CAE) e o Nutricionista são agentes do PNAE e são também responsáveis por zelar pela qualidade dos alimentos [5,6].

Uma das estratégias para garantir qualidade higiênico-sanitária e a conformidade dos alimentos com a legislação sanitária baseia-se na adoção das Boas Práticas de Produção pelos serviços de alimentação [7]. Nesse sentido, as Boas Práticas encontram-se abordadas pela Portaria Interministerial no 1.010 [8] como um dos eixos prioritários para a definição da promoção da alimentação saudável nas escolas e como pré-requisito para o alcance de uma alimentação saudável e para a garantia da segurança sanitária dos alimentos e das refeições.

Contudo, o panorama atual, descrito em diversos estudos sobre a qualidade higiênico-sanitária na produção da alimentação escolar, aponta para divergências entre a operacionalização do PNAE nas escolas e o que é estabelecido legalmente. Inúmeras falhas têm sido detectadas nas unidades de alimentação escolar referentes ao fluxo de produção não linear, à ventilação, à iluminação, à proteção contra pragas e mesmo à disponibilidade de prateleiras para arrumação e separação dos produtos, devido ao improviso na criação dos espaços [9-13].

Cardoso et al. [14], em estudo realizado em escolas públicas da rede estadual e municipal de Salvador, Bahia (BA), verificaram que parte expressiva (57\%) das Unidades avaliadas foi classificada no nível insatisfatório de atendimento aos requisitos normativos, e os aspectos que mais contribuíram para o baixo desempenho compreenderam aqueles referentes à edificação e às instalações, controle de qualidade da água, manipuladores, preparo e exposição dos alimentos, apresentando impactos diretos e indiretos em relação à inocuidade da alimentação escolar.

Atualmente, o município de Salvador é responsável por 413 escolas públicas de ensino infantil e fundamental, distribuídas em 11 Coordenadorias Regionais de Educação (CRE), com uma média de aproximadamente 38 escolas por CRE [15]. A gestão do PNAE no município ocorre de forma centralizada pela Entidade Executora (EE) e conta com a participação de um nutricionista Responsável Técnico (RT) e 3 nutricionistas no Quadro Técnico (QT). A logística de 
entrega dos alimentos se dá de forma direta: fornecedores - unidades escolares (UE), não existindo um almoxarifado central. As escolas possuem cantinas onde os alimentos são armazenados, preparados e distribuídos aos alunos.

Considerando que a qualidade dos alimentos resulta de uma série de controles que devem ser exercidos durante todo o processo da produção; que nas unidades escolares a recepção e o armazenamento compreendem as primeiras etapas responsáveis pela determinação da qualidade, e que há insuficiência de estudos sobre o tema associando a perspectiva quantitativa e qualitativa, este trabalho teve como objetivo caracterizar o controle de qualidade higiênicosanitário na recepção e no armazenamento de alimentos, em escolas públicas da CRE - Pirajá, em Salvador.

\section{MATERIAIS E MÉTODOS}

Trata-se de um estudo de caso, com abordagem quantitativa e qualitativa, realizado em três escolas públicas municipais da CRE-Pirajá, Salvador, no período de junho a outubro de 2009, como parte do projeto "Reorientação da operacionalização da alimentação escolar do município de Salvador e região metropolitana" - desenvolvido pela Universidade Federal da Bahia (UFBA), em parceria com o FNDE e a Prefeitura Municipal de Salvador.

O referido projeto contemplava um total de 54 escolas de três CRE e a escolha das três unidades escolares, deste universo, para o presente estudo se deu por conveniência.

Em atendimento à Resolução do Conselho Nacional de Saúde no 196, do MS [16], o estudo foi submetido ao Comitê de Ética em Pesquisa da Escola de Nutrição da UFBA (Parecer 07/09). A coleta de dados e informações contemplou o uso de uma lista de verificação, entrevistas semi-estruturadas com as gestoras (diretoras) escolares, merendeiras e secretária escolar, observação participante e análise documental.

A lista de verificação foi elaborada a partir da Resolução da Diretoria Colegiada - RDC no $275^{[17]}$ e da RDC no 216 [7] e compreendeu duas categorias de informações, sendo a primeira referente à identificação e caracterização da unidade de alimentação escolar e a segunda relativa ao controle de qualidade higiênico- sanitário. A segunda categoria foi organizada em 4 blocos de questões, abarcando os seguintes aspectos: 1 . Recepção dos alimentos; 2. Armazenamento dos alimentos não perecíveis; 3. Armazenamento dos alimentos congelados; e 4. Armazenamento dos alimentos hortifrutigranjeiros. Em cada escola, a aplicação da lista de verificação ocorreu em apenas um dia, remetendo-se também o preenchimento dos dados às informações obtidas durante a condução da observação participante.

Os dados da lista de verificação foram tabulados utilizando-se o Programa Excel 2003, da Microsoft Windows, sendo adotada a análise descritiva. $\mathrm{O}$ percentual de adequação final de cada Unidade de Alimentação Escolar (UAE) foi calculado a partir do somatório dos pontos obtidos nas questões em conformidade, dividido pelo somatório dos pontos possíveis, sendo subtraídos do denominador os pontos referentes às questões onde foi admitida a resposta não se aplica (NA), conforme mostra a equação abaixo. $\mathrm{O}$ mesmo se deu para o cálculo do percentual de adequação por bloco.

$$
\% \text { de adequação }=\frac{\Sigma \text { pontos positivos }}{\Sigma \text { pontos possíveis }-\Sigma N A} \times 100
$$

De acordo com a pontuação obtida, as escolas foram classificadas em cinco grupos, em relação à condição higiênico-sanitária: crítico, com atendimento inferior a $30 \%$ do total dos itens avaliados; insatisfatório, com atendimento maior ou igual a 30 e menor que $50 \%$; regular, com atendimento maior ou igual a 50 e menor que $70 \%$; bom, com atendimento maior ou igual a 70 e menor que $90 \%$; e excelente, quando maior ou igual a 90\%. A adoção desses grupos de classificação baseou-se no estudo de Cardoso et al. [14].

Em cada escola foram entrevistadas uma gestora escolar e uma merendeira, sendo que em uma das escolas foi entrevistada também uma secretária escolar, por ser esta responsável pela realização do controle do estoque dos alimentos. Os depoimentos foram gravados e transcritos após a assinatura do Termo de Consentimento Livre e Esclarecido (TCLE) pelos sujeitos da pesquisa.

Foram utilizadas ainda outras fontes de dados tais como: diários de campos, Ordens de Fornecimento de alimentos (OF) do período de janeiro a julho de 2009, registros do Sistema de controle de estoque 
(Mapa on-line) e do caderno da alimentação escolar, utilizado pelas merendeiras para anotar o número de alunos presentes, o cardápio do dia, os itens retirados do estoque e a sua quantidade.

\section{RESULTADOS E DISCUSSÃO}

\section{Caracterização das escolas}

A Tabela 1 apresenta a caracterização das escolas quanto ao porte, descrevendo o número de alunos matriculados, de refeições produzidas e de funcionários da UAE. Como se nota, as escolas A e B apresentam os maiores números de alunos matriculados e são classificadas como de grande porte especial, ao passo que a escola $C$ possui menor número de alunos e é classificada como de grande porte. $\mathrm{Na}$ escola A, o controle do número de refeições não era realizado no turno vespertino nem no noturno, o que pode resultar tanto em uma produção de alimentos insuficiente como também em perdas de alimentos pela produção excessiva.

Tabela 1. Caracterização das escolas quanto ao porte, número de alunos, de refeições e de funcionários, Salvador (Bahia), 2009.

\begin{tabular}{lccc}
\hline Caracterização & Escola A & Escola B & Escola C \\
\hline Porte* & Grande porte especial & Grande porte especial & Grande porte \\
\hline Número de alunos matriculados/turno & & & 96 \\
\hline Matutino & 388 & 315 & 110 \\
Vespertino & 372 & 311 & 0 \\
Noturno & 183 & 137 & 206 \\
Total & 943 & 763 &
\end{tabular}

\section{Média do número de refeições produzidas/turno}

\begin{tabular}{lccc}
\hline Matutino & 300 & 196 & 70 \\
Vespertino & N/C** & 205 & 86 \\
Noturno & N/C** & 65 & 0 \\
Total & N/C** & 466 & 156 \\
\hline
\end{tabular}

Número de funcionários da Unidade de Alimentação Escolar (UAE)/turno

\begin{tabular}{lccc}
\hline Matutino & 6 & 3 & 2 \\
Vespertino & 7 & 3 & 2 \\
Noturno & 4 & 1 & 0 \\
Total*** & 10 & 4 & 2
\end{tabular}

* Classificação segundo a Secretaria Municipal de Educação e Cultura (SECULT) ${ }^{[15]}$.

** N/C: não controlado por meio de registros.

*** Total não corresponde ao somatório do número de funcionários por turno, visto que um mesmo funcionário pode ter jornada de $8 \mathrm{~h} /$ dia. 
Com relação ao número de funcionários responsáveis pela produção da alimentação escolar, verificou-se desproporção entre as escolas A e B, visto que elas apresentavam o mesmo porte. Em todas as escolas os funcionários efetivos da rede municipal de ensino possuíam jornada de trabalho de $6 \mathrm{~h} / \mathrm{dia}$, ao passo que os terceirizados (presentes na totalidade das escolas pesquisadas), cumpriam jornada de $8 \mathrm{~h} / \mathrm{dia}$. Ressalta-se, neste contexto, que os funcionários responsáveis pela produção da alimentação escolar também realizavam a higienização da cozinha e de outras áreas da escola, uma condição que pode comprometer a qualidade higiênico-sanitária da alimentação escolar além de sobrecarregar os funcionários.

\section{Resultados globais da lista de verificação}

Os resultados de classificação global das escolas quanto ao Controle de qualidade na recepção e no armazenamento dos alimentos são exibidos na Figura, sendo observado um percentual de adequação insatisfatório $(>30$ e $<50 \%)$ para as três escolas. Cardoso et al. [14], em estudo realizado em escolas públicas municipais e estaduais de Salvador, encontrou uma situação de não-conformidade semelhante para a maior parte das unidades investigadas (57\%).

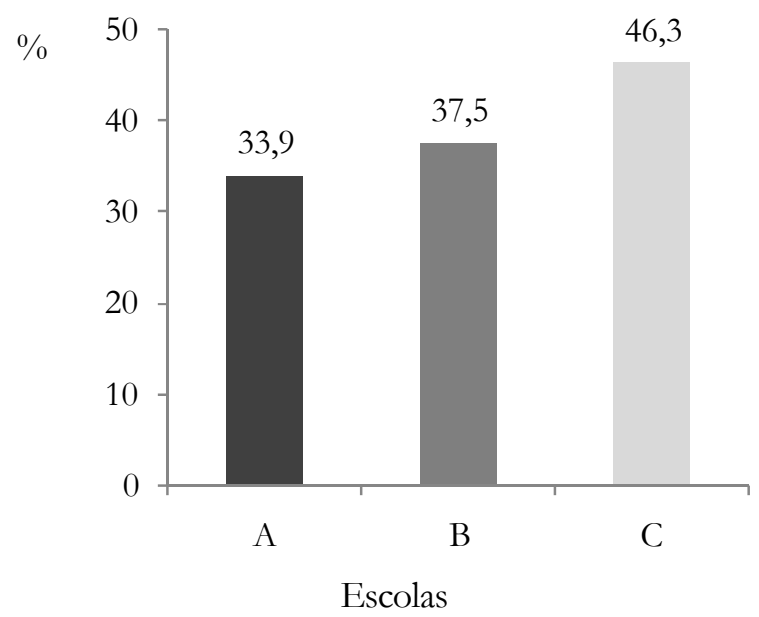

Figura. Percentual de classificação global das escolas da Coordenadoria Regional de Educação - Pirajá, quanto ao controle de qualidade na recepção e no armazenamento dos alimentos, Salvador (Bahia), 2009.

\footnotetext{
Resultados por bloco de avaliação da lista de verificação
}

$\mathrm{Na}$ Tabela 2 são descritos os resultados de classificação das escolas, agrupados em blocos. $\mathrm{Na}$ etapa de recepção, os itens mais inadequados nas escolas foram as ausências: de monitoramento das condições de higiene dos veículos; de horários préestabelecidos para as entregas; de controle de temperatura dos gêneros perecíveis e de infraestrutura física para o recebimento. No armazenamento dos alimentos foram identificados: falta de infraestrutura física dos depósitos; de controle de validade dos produtos; além da insuficiência de equipamentos para armazenamento dos gêneros perecíveis. Verifica-se que os aspectos relativos à recepção dos alimentos e ao armazenamento de hortifrutigranjeiros foram os que mais contribuíram para o baixo nível de adequação global de todas as escolas. A análise conjunta destes resultados, além de refletir o não atendimento à legislação, revela também a possibilidade de riscos à saúde dos escolares.

Nas próximas seções do artigo (recepção e armazenamento dos alimentos) encontram-se detalhados os resultados observados em cada bloco da lista de verificação, sendo estes corroborados pela observação participante e pelas entrevistas semiestruturadas.

\section{Recepção dos alimentos}

A recepção constitui um ponto de controle na cadeia produtiva dos alimentos e, por ser a primeira etapa a ocorrer na unidade escolar, é imprescindível o estabelecimento de critérios para o seu monitoramento, sob pena de comprometer a qualidade das demais etapas do processo e a inocuidade do produto final.

Nesta etapa é importante o estabelecimento de horários diferentes para cada fornecedor. Caso não seja possível, deve-se priorizar o recebimento dos alimentos refrigerados, seguidos dos congelados e por último os alimentos que possam ser mantidos em temperatura ambiente. As condições do transporte, do entregador e das embalagens dos alimentos devem ser rigorosamente monitoradas, assim como a rotulagem das embalagens, as características e a temperatura dos produtos [19].

Nas três escolas avaliadas, o monitoramento dos alimentos na recepção era de responsabilidade do gestor, do vice ou do secretário escolar, embora acontecesse das merendeiras conferirem os alimentos e os responsáveis apenas assinarem as $\mathrm{OF}$. 
Tabela 2. Percentual de adequação das escolas da Coordenadoria Regional de Educação - Pirajá, por bloco de avaliação, Salvador (Bahia), 2009.

\author{
$\%$ de adequação por bloco
}

\begin{tabular}{|c|c|c|c|c|}
\hline Escola & Recepção & $\begin{array}{l}\text { Armazenamento de } \\
\text { Alimentos } \\
\text { Não perecíveis* }\end{array}$ & $\begin{array}{l}\text { Armazenamento de } \\
\text { Alimentos } \\
\text { Congelados }\end{array}$ & $\begin{array}{l}\text { Armazenamento de } \\
\text { Alimentos } \\
\text { Hortifrutigranjeiros }\end{array}$ \\
\hline A & 31,25 & 42,86 & 33,33 & 20,00 \\
\hline B & 31,25 & 52,38 & 33,33 & 20,00 \\
\hline C & 31,25 & 52,63 & 77,78 & 30,00 \\
\hline Média & 31,25 & 49,29 & 48,15 & 23,33 \\
\hline
\end{tabular}

De acordo com as observações das atividades do PNAE nas escolas, nota-se que a maior ênfase na recepção dos alimentos era dada à conferência da marca, da validade e da quantidade dos produtos com a OF. Não era realizado nenhum monitoramento ou registro das condições de higiene do veículo e do entregador e não havia horários pré-estabelecidos e ordem para a recepção por tipo de alimento. Muitas vezes os gêneros eram entregues no horário de distribuição das refeições, dificultando a conferência adequada dos produtos.

Ainda que instruções de trabalho referentes ao recebimento de alimentos estivessem afixadas nas paredes das cozinhas, o controle de temperatura dos gêneros perecíveis não era realizado em nenhuma das escolas, uma vez que não dispunham de termômetros.

Com relação à infraestrutura para o recebimento dos alimentos, verificou-se não haver nas escolas uma área reservada para este fim. $\mathrm{O}$ mesmo foi observado por Cardoso et al. ${ }^{[14]} \mathrm{em} 98,3 \%$ das escolas avaliadas. No presente estudo notou-se também não haver área de pré-lavagem de vegetais e balança própria das Unidades - o peso dos hortifrutigranjeiros era conferido utilizando-se a balança do entregador.

A qualidade da matéria-prima é outro aspecto que deve ser monitorado no ato do recebimento.
Segundo Guimarães et al. [20], a adoção de tal medida, associada ao controle do processo produtivo, é fundamental para minimizar a contaminação e gerar mais confiabilidade no produto final. Em entrevista com a gestora da escola B, quando questionada sobre os critérios utilizados para avaliar a qualidade dos hortifrutigranjeiros, a mesma respondeu:

"... por ser a maioria aqui dona de casa, a gente observa assim. O básico! Se não tem nada ruim... Com nenhum bichinho... Essa coisa toda, né? Về a aparência assim... da melhor maneira possivel" (GESTORA ESCOLA B).

Pela fala desta gestora percebe-se que, nesta escola, o monitoramento no recebimento dos alimentos se dá de forma bastante empírica. Guimarães et al. [20] ressaltam a necessidade de adoção de sistemática rigorosa para o recebimento das mercadorias, por meio do estabelecimento de padrões que sejam aplicados durante a seleção de amostras das mercadorias entregues, comparando-as e recusando aquelas que se apresentarem fora das especificações técnicas ou com suspeita de comprometimento da qualidade sanitária.

Quanto à qualidade dos alimentos, os gestores das escolas B e C consideraram que tem havido melhorias nos últimos anos, embora as merendeiras das 
escolas A e B tenham feito ressalvas para alguns produtos:

'Depois de vários ajustes com o pessoal da CAS (Coordenadoria de Ações Socioeducativas) ${ }^{1}$, a gente vê que há uma preocupação em cada vez, mais qualificar o que está vindo pra escola. Então, a merenda hoje é de boa qualidade. Agora, como se trabalha com fornecedores, tem-se que ter um cuidado de estar sempre atento ao que está vindo... essa preocupação épermanente" (GESTORA ESCOLA B).

"Mas o que a gente percebe em termo de qualidade... melhorou muito a qualidade da merenda escolar, a qualidade dos gêneros..." (GESTORA ESCOLA C).

"Algumas qualidades são péssimas! O feijão, a farinha, o peixe moído e em cubo nunca vieram estragados, mas os alunos não aceitam” (MERENDEIRA ESCOLA A).

" [...] a carne moída mesmo... Por sinal, tem vez que vem muito gordurosa [...] a qualidade do feijão mesmo: o outro feijão era trabalhoso por que en catava, botava de molho, mas o feijão era duro! Pra cozinhar de manhã... Pra chegar 9:40h você está com a merenda ali... Às vezes a gente chega aqui antes de $6 \mathrm{~h}$ da manhã... E o feijão... Um trabalho! É isso que eu digo, eles mandam as coisas de várias qualidades. Já esse feijão que a gente está usando está ótimo!” (MERENDEIRA ESCOLA B).

É interessante perceber as diferentes associações feitas pelas merendeiras ao avaliarem a qualidade dos alimentos. Elas relacionam qualidade à aceitação pelos alunos, à facilidade na realização das tarefas, bem como às características sensoriais dos produtos.

Quando da ocorrência de inadequações e/ou qualidade inferior dos produtos ao que era especificado nas OF, verificaram-se semelhanças nas ações adotadas pelos gestores, os quais geralmente comunicavam o fato à CAS por telefone, colocavam as observações nas OF e efetuavam a devolução do produto.

\section{Armazenamento de alimentos}

O armazenamento de alimentos compreende outra etapa importante do controle de qualidade de uma unidade de alimentação e nutrição, na qual as matérias-primas devem permanecer em condições que

1 Coordenadoria de Ações Socioeducativas (CAS), vinculada à Secretaria Municipal de Educação, Cultura, Esporte e Lazer do município de Salvador (Bahia). garantam a proteção contra a contaminação, a redução das perdas da qualidade nutricional e a não deterioração do produto. Para tanto, deve-se manter o controle da temperatura, a limpeza, a rotatividade dos estoques e a ventilação, de modo a assegurar a manutenção de bons padrões de higiene, evitando o desperdício de alimentos e consequentes perdas econômicas, além de prevenir possíveis intoxicações e infecções alimentares [21].

Durante o armazenamento devem ser respeitadas as características de perecibilidade dos produtos.

\section{Armazenamento de alimentos não perecíveis}

Os alimentos não perecíveis podem ser armazenados à temperatura ambiente e suas embalagens devem apresentar-se íntegras, próprias para cada tipo de alimento, dentro do prazo de validade e com identificação correta nos rótulos [22].

A rotatividade dos estoques se faz necessária, pois os produtos estocados, mesmo quando empacotados ou enlatados, não se conservam indefinidamente. Assim, deve-se dar saída aos produtos mais velhos em primeiro lugar, evitando armazenar produtos por mais tempo que o necessário [23], procedimento que foi relatado por gestoras e merendeiras:

"A arrumação é feita se colocando na frente tudo que vai vencer primeiro. Atrás a gente coloca o que vai vencer por último. A gente tem esse cuidado justamente pra não estar tendo que devolver nenhum gênero e perdendo gênero também" (GESTORA ESCOLA B).

"[...] Primeiro vamos usando o que já está na casa. A gente também coloca separado o que tem validade diferente" (MERENDEIRA ESCOLA A).

Contudo, a observação em campo permitiu constatar certa incoerência na fala desta merendeira, visto que foi verificada na Unidade a perda de alimentos por expiração do prazo de validade. Os produtos não estavam devidamente organizados e nem com prazo de validade afixado em local visível. $\mathrm{Na}$ escola B, por sua vez, apesar da utilização de etiquetas de validade para os alimentos armazenados, constatouse que alguns gêneros não possuíam essa identificação.

Com relação à infraestrutura do depósito e das condições de armazenamento dos alimentos não 
perecíveis, a escola $\mathrm{B}$ dispunha de um depósito de alimentos relativamente maior que o da escola A, porém estavam presentes no espaço equipamentos e utensílios em desuso e um freezer que contribuía para a elevação da temperatura e umidade do ambiente. Ambas apresentavam as seguintes inadequações: portas sem fechamento automático e sem proteção no rodapé; presença de caixas de papelão; ventilação insuficiente e temperatura elevada; ausência de telas milimétricas nas aberturas, favorecendo a presença de pragas como roedores, baratas, aranhas e formigas.

No trabalho conduzido por Piragine [10] verificou-se que $100 \%$ das escolas não adotavam medidas de prevenção contra pragas e Cardoso et al. [14] constaram que pouco mais da metade das escolas $(54,5 \%)$ contavam com procedimentos de desinsetização sistemática e em $46 \%$ foram encontrados insetos e vestígios na área de produção. $\mathrm{O}$ mesmo quadro pode ser observado em duas das escolas avaliadas no presente estudo (escolas A e B).

Quando questionadas sobre o que achavam da estrutura do depósito das suas respectivas escolas, as merendeiras das escolas A e B responderam:

"A cozinha da escola é pequena. O depósito é um ovinho! [...] A cozinha está horrivel. O biscoito mesmo está tudo do lado de fora porque não tem como guardar! A gente faz o que pode..." (MERENDEIRA ESCOLA A).

"Praticamente o depósito se torna pequeno. Por que agora mesmo chegou bolacha e eu nem sei como vai ser arrumado. Botei tudo em cima da cadeira com as caixas. Tá usando a de lá [do depósito] pra ir esvaziando o lugar pra colocar..." (MEREDEIRA ESCOLA B).

A escola C, por sua vez, dispunha da menor área física destinada ao armazenamento dos alimentos não perecíveis. Esta área localizava-se dentro da sala da direção e apresentava várias inadequações, incluindo: ausência de revestimento liso e impermeável nas paredes; uso de prateleiras de madeira; ventilação natural insuficiente, devido à ausência de janelas, sendo utilizada a ventilação forçada com o auxilio de um ventilador; alimentos estocados próximos aos materiais didáticos e produtos descartáveis, empilhados de forma imprópria. A ciência das inadequações da estrutura foi confirmada no discurso da gestora local:

'Precária! [a estrutura] Porque en acredito que se houvesse aquilo que está proposto para esta escola... Se já houvesse acontecido, a gente teria condiḡês de armazenar melhor os itens. Não estão [os alimentos] em lugar adequado por que nós não temos depósito de merenda. Essa é uma luta desde os anos anteriores, amenizou com as prateleiras, mas a gente sabe aqui, que dentro de uma sala de diresão, não é o local adequado para mantermos a merenda escolar [...] quando você não tem um local adequado de armazenamento... Você tem aí um arranjo" (GESTORA ESCOLA C).

\section{Armazenamento de alimentos congelados}

Os alimentos congelados devem ser mantidos em temperatura igual ou inferiores a $-18^{\circ} \mathrm{C}$ [7]. Nos casos de armazenamento sob baixas temperaturas, alimentos de tipos diferentes podem ser armazenados em um mesmo equipamento, desde que embalados, separados e identificados corretamente ${ }^{[19]}$.

Com relação ao armazenamento dos alimentos congelados, verificou-se que as escolas A e B apresentaram inadequações semelhantes, tais como: freezers em número insuficiente e superlotados com produtos diversos (carne, frango, peixe, tempero batido) e sem a devida separação, aumentando o risco de contaminação cruzada - uma situação que se assemelha à encontrada por Farche et al. ${ }^{[1]} \mathrm{em}$ escolas da rede pública de Franca (SP); higiene insatisfatória e acúmulo de gelo, o que contribui para elevação da temperatura de conservação dos alimentos. Na escola B foi constatada também a presença de alimentos embalados em caixas de papelão juntos a alimentos em embalagens primárias no freezerer.

Piragine ${ }^{[10]}$ constatou em seu estudo que, para os equipamentos de conservação dos alimentos sob frio, apenas 30\% (doze escolas) apresentaram adequada higiene e funcionamento, pois na grande maioria das escolas não eram realizados o descongelamento e a limpeza regularmente. Situação semelhante, no presente estudo, pôde ser constatada em duas das escolas avaliadas (escolas A e B), uma vez que nestas não havia uma frequência programada de descongelamento/higienização dos equipamentos.

No presente estudo, a insuficiência de equipamentos para conservação dos alimentos foi relatada pela gestora da escola B:

"Com relação a equipamentos... Freezers mesmo... Estamos necessitando de freezers [...] foi um sufoco semana passada quando recebemos frango e carne moída numa quantidade imensa! [...] O problema não é que esteja sobrando 
merenda, o problema é que eu não tenho como armazenar de forma confortável. Eu necessito de freezer, de outra geladeira... Inclusive já existe uma solicitação na Secretaria [...] Há um ano eu até aluguei freezer na comunidade. Hoje eu não faço isso. Até por conta da correria, da agonia, eu não tenho como... Eu coloco na ordem de fornecimento o que recebeu e que deu pra armazenar na escola e devolvo o restante".

A escola C, por sua vez, apresentou maior percentual de adequação para o armazenamento dos alimentos congelados em relação às escolas A e B. O freezer presente na Unidade atendeu à demanda durante o período de observação do presente estudo, encontrava-se em boas condições de higiene e os alimentos eram mantidos devidamente separados por prateleiras (freezer vertical). No entanto, o equipamento apresentava-se oxidado na parte exterior, necessitando, portanto, de manutenção.

O controle de temperatura durante $\mathrm{O}$ armazenamento sob congelamento não era realizado pelos gestores/merendeiras em nenhuma das três unidades escolares investigadas, visto que os equipamentos não possuíam medidores de temperatura, conforme preconizado em legislação.

\section{Armazenamento de alimentos hortifrutigranjeiros}

Os hortifrutigranjeiros, depois de selecionados, podem ser armazenados tanto sob refrigeração, até $10^{\circ} \mathrm{C}$, como à temperatura ambiente. Esta escolha dependerá do tipo de hortifrutigranjeiro que está sendo estocado. No caso de armazenamento em temperatura ambiente, devem ser utilizadas caixas plásticas, que permitam a circulação de ar e sejam mantidas sobre estrados fenestrados ou empilhadas sobre uma caixa vazia, em local livre de sujidades [24].

As condições de armazenamento dos hortifrutigranjeiros constituíram o bloco que mais comprometeu o desempenho global das UAE avaliadas, uma vez que os critérios citados acima não foram observados em nenhuma delas. A insuficiência de equipamentos foi também um fator limitante para o armazenamento dos hortifrutigranjeiros em todas as escolas.

Os hortifrutigranjeiros eram armazenados, em sua maioria, à temperatura ambiente, dentro de vasilhames ou diretamente no chão, pois as UAE não dispunham de caixas plásticas vazadas nem de estrados:
" [...] en botava na geladeira [os hortifrutigranjeiros], pegava um cuscuzeiro grande, arrumava tudo... Quando vinha banana da terra, banana sem ter onde botar tinha que arrumar tudo ali no chão, no cantinho da cozinha..."(MERENDEIRA B).

Antes de serem armazenados sob refrigeração, verificou-se que os hortifrutigranjeiros não eram devidamente higienizados e organizados, aumentando o risco de contaminação cruzada.

\section{Fatores limitantes para o controle de qualidade na recepção e no armazenamento dos alimentos}

Além da deficiência na estrutura física das UAE, da insuficiência de equipamentos destinados ao armazenamento dos alimentos e da falta de rotatividade dos estoques, já mencionados, a não regularidade na entrega dos alimentos constituiu outro fator crítico na realização do controle de qualidade nas UAE.

Pela análise das OF do período de fevereiro a julho de 2009, verificou-se que alguns gêneros, em especial os congelados e hortifrutigranjeiros, não eram entregues regularmente. Num período de seis meses foram realizadas apenas duas entregas de hortifrutigranjeiros nas escolas A e C e três na escola B. Os alimentos congelados foram entregues, no mesmo período de seis meses, apenas duas vezes na escola $C$, quatro e seis vezes nas escolas A e B, respectivamente. As quantidades entregues, muitas vezes, superavam a capacidade de armazenamento dos equipamentos, resultando em improvisos que comprometiam a qualidade higiênico-sanitária dos alimentos, bem como contribuíam para perdas, conforme mostram os discursos abaixo:

"Com relação à frequência, alguns gêneros demoram muito tempo mesmo! Às vezes fica um tempão sem vir. As vezes estraga [os hortifrutigranjeiros] ai a gente tem que jogar fora!" (MERENDEIRA A).

"[...] Por que ele mandava tudo de vez! Então... Quer dizer, não tem nem lugar pra botar e nem... Por que se toda semana eles mandassem um pouco, a gente ia usando ali... Mas quando vem é tudo de vez! Agora não, mas era abóbora, banana da terra, inhame, batata, era tanta coisa que a gente ficava sem... A cozinha ai ficava cheia. Era melancia... A cozinha ai ficava cheia! Por que não tinha espaço, tinha que botar no cantinho aí do chão. Se não tinha aonde botar!" (MERENDEIRA ESCOLA B). 
Outra implicação da frequência irregular da entrega dos gêneros alimentícios nas escolas era o não cumprimento do cardápio proposto. Visto que existiam períodos de escassez de alimentos nas escolas e outros de abundância, o cardápio constantemente sofria ajustes e o improviso muitas vezes comprometia a qualidade da alimentação escolar servida aos alunos:

" [...] vêm gêneros descascados. A frequência dos gêneros é uma questão de política. A frequência deixa a desejar, depende da licitação, falta, não tem no depósito, sempre faltam gêneros..." (GESTORA ESCOLA A).

“[...] temos alimentação que não está sendo preparada por falta de hortifrutigranjeiro ou então a diretora põe com o dinbeiro dela (SECRETÁRIA ESCOLA B).

"[...] às vezes frutas demoram muito, tempero demora muito, a gente tem que ficar pedindo ao aluno pra trazer às vezes e... Farinha, feijão falta sempre também... E às vezes também é carne, demora muito também pra chegar. São esses itens que demoram e são os que necessitamos mais né?" (MERENDEIRA ESCOLA C).

Um planejamento inadequado da logística de entrega dos alimentos em nível central dificulta o controle de qualidade no armazenamento dos gêneros nas escolas. Igualmente, a ausência de um controle efetivo do estoque nas escolas também compromete o planejamento em nível central, uma vez que inexiste interligação das atividades desenvolvidas pelos dois níveis, tornando-se um ciclo vicioso.

Quando questionadas se realizavam algum tipo de controle de estoque, as gestoras responderam positivamente, ainda que nem todas as escolas atualizassem o preenchimento do Mapa on-line, disponibilizado pela Secretaria Municipal de Educação e Cultura (SECULT):

'Lógico! Se não bouver controle de estoque como é que a gente vai fazer mapa da merenda? Controle de estoque ele é diário, cada saída é computada em um mapa. O mapa que é manuscrito e depois esse mapa é lançado no Sistema [...] aqui na escola nós primamos muito por manter o nosso mapa da merenda atualizado, então não chegam a faltar gêneros" (GESTORA ESCOLA C).

"Realizo [controle de estoque] nessa contagem, sempre na limpeza do depósito [...] Tem a questão do mapa da merenda... O preenchimento está atrasado, foi atualizado até
2007. Mas está sendo feito o controle manual... Tem o caderno de anotação da merenda" (GESTORA ESCOLA A).

O controle manual da saída dos gêneros era feito tanto pelos gestores quanto pelas merendeiras, as quais utilizavam um caderninho chamado caderno da alimentação escolar. Em tese, as informações desse caderno deveriam servir de base para registro no Sistema de controle on-line da SECULT.

O Sistema Informatizado da Alimentação Escolar está disponível nas escolas de forma on-line, por isso é também conhecido como Mapa on-line. Este Sistema permite a integração das escolas com o setor de alimentação escolar da SECULT, o controle dos estoques e do número de refeições servidas, e a realização da expedição de gêneros e materiais. Nas escolas, as gestoras e/ou secretárias devem fazer o lançamento dos alimentos que chegam e a baixa diária dos gêneros alimentícios utilizados. No final do mês deve ser feito o fechamento mensal, deixando registrados no Sistema os gêneros que estão no almoxarifado físico da UAE. Estão informatizados também o consumo de material de limpeza e as solicitações de gás.

Apesar das escolas possuírem o Mapa on-line, nem todas o utilizavam corretamente. Na escola A, por exemplo, a gestora não se mostrava comprometida com o seu preenchimento e parecia não ver a importância do mesmo:

“... seria importante se suprisse a carência de gêneros, mas eu não sei falar muito, pois eu deixo a desejar na digitação" (GESTORA ESCOLA A).

As demais gestoras, no entanto, reconheciam a importância do Sistema e o viam como uma forma da SECULT monitorar a movimentação dos gêneros alimentícios na escola e viabilizar os itens para a execução do cardápio planejado:

"Ele [o Mapa] é importante porque dá toda a visão do consumo de merenda na escola, os itens que estão faltando e os itens que nós temos e proporciona a realização de um cardápio balanceado na medida do possivel" (GESTORA ESCOLA C).

A qualificação dos funcionários da UAE é outro fator imprescindível para a garantia da qualidade dos alimentos. Nas escolas avaliadas, as merendeiras entrevistadas afirmaram já ter participado de algum 
treinamento ministrado por nutricionistas da SECULT, referente às Boas Práticas de manipulação dos alimentos, no entanto, a frequência de realização desses treinamentos foi superior a um ano.

Observou-se que as merendeiras, apesar de terem conhecimentos sobre as recomendações para a recepção e o armazenamento dos alimentos, não aplicavam ou aplicavam pouco esses conhecimentos nas suas rotinas de trabalho, possivelmente pela falta de condições e/ou ainda pela falta de hábito em adotarem as Boas Práticas, fato também relatado por Pistore \& Gelinskib [25]. Faz-se necessário, portanto, que a capacitação dos manipuladores de alimentos não seja realizada de forma pontual e sim periódica, constituindo-se uma rotina do serviço de alimentação [12,26]; adicionalmente, devem ser viabilizadas condições estruturais e materiais para que os funcionários possam executar o que lhes está sendo ensinado [25].

Costa et al. ${ }^{[27]}$ em estudo sobre a concepção educacional do treinamento de merendeiras, com análise de registros entre os anos de 1956 a 1994, no Rio de Janeiro (RJ), atribuíram a aceitação ou rejeição dos conteúdos trabalhados a outros fatores, tais como: diferença de sentido e finalidade atribuídos pelas merendeiras às informações discutidas; ao papel que elas entendem desempenhar na escola; à relação que estabelecem com o educador; à compreensão que desenvolvem sobre a estrutura na qual estão inseridas e à relação que fazem entre o conteúdo desenvolvido nos cursos e a vida que levam fora da escola.

Segundo estes autores [27], toda vez que se desconsideram esses aspectos durante os cursos de treinamento e que há uma concentração na transmissão de informações sobre higiene e organização do serviço de alimentação, corre-se o risco de o discurso não encontrar a receptividade desejada. Essa situação pode ser observada na fala da merendeira da escola B:

"Eu acho que o pessoal da nutrição não quer que a gente forre as prateleiras, mas eu acho que deveria pra arrumar... Digamos assim: chegou bolacha, a gente pegar a caixa da bolacha, abrir assim e forrar, por que eu acho que a frieza é que cria o gorgulho! Por que o piso é frio. O piso é frio... Eu acho isso, né? Que deveria pegar a caixa limpinha que vem e forrar, assim, no lugar que vai botar os alimentos e arrumar em cima, só pra forrar" (MERENDEIRA ESCOLA B).

Nesse sentido, nota-se certa resistência da merendeira em aceitar as orientações recebidas, que parece estar associada à sua percepção sobre limpeza e higiene na manipulação dos alimentos. Segundo Santos Filho et al. [13], deve-se ponderar fatores culturais que permeiam os valores desses funcionários. Muitos trazem como conceito de higiene apenas a ausência de sujeira, porém isso não é suficiente para garantir a segurança dos alimentos. Por sua vez, essa compreensão é formada no contexto da cultura, especialmente, no ambiente doméstico.

Tanto o baixo nível de qualificação dos funcionários quanto o número reduzido destes nas UAE caracterizam-se, de forma geral, como entraves à realização de um serviço de qualidade. No entanto, verificou-se que a escola $\mathrm{A}$, apesar de possuir o maior quadro de funcionários, foi a que apresentou o pior desempenho em todos os itens avaliados. Neste caso, verificou-se que as atribuições dos funcionários não estavam bem definidas e não havia uma supervisão mais próxima do serviço por parte do gestor escolar:

"A diretora não fica no pé da gente. Ela só vem quando está pronto!” (MERENDEIRA ESCOLA A).

A escola C, por sua vez, teve o maior percentual de adequação global e por bloco de avaliação e contava apenas com dois funcionários envolvidos com a alimentação escolar; no caso, a gestora escolar demonstrava participação ativa em todo o processo:

" [...] Se for, vamos dizer, um fardo, a merendeira não aguenta. Ai eu peço que um funcionário homem venha e arrume, mas é tudo com a minha inspeção. Ele fica ali arrumando com a minha presença ou da secretária e quando a merendeira também está disponivel ela vem e vê, mas sempre o recebimento, a guarda e tudo são da direção da escola. Agora, ela está autorizada a entrar, a pegar algum alimento que ela necessite desde que ela anote tudo que ela retirou” (GESTORA ESCOLA C).

Apesar de os gestores escolares já desempenharem múltiplas funções, seu comprometimento e participação na execução do PNAE nas escolas são de fundamental importância para a garantia da qualidade em cada etapa do processo. Para tanto, eles devem possuir competências e habilidades que lhe permitam exercer forte liderança para adotar medidas que levem à construção de uma escola efetiva, com base em uma cultura de sucesso, gerada e gerenciada no interior da própria escola, alinhada às normas do Sistema Municipal de Ensino e 
aos princípios de uma gestão democrática e participativa [28].

Além dos gestores escolares, o CAE e o Nutricionista, agentes do PNAE, são também responsáveis por zelar pela qualidade dos alimentos nas escolas. Porém, com apenas quatro nutricionistas, responsáveis pela totalidade da rede de ensino do município, esta função de supervisão não era realizada com regularidade, sendo priorizadas visitas escolares em caso de suspeitas de improbidade na execução do PNAE, denunciadas pela comunidade ou solicitação por parte dos gestores. O suporte às escolas era dado, na maioria das vezes, por telefone. Durante o período de observação do presente estudo, não foram verificadas visitas dos nutricionistas ou de membros do CAE às escolas.

\section{Fatores facilitadores para o controle de qualidade na recepção e no armazenamento dos alimentos}

Em meio a tantos fatores limitantes ao controle de qualidade na recepção e no armazenamento dos alimentos, gestoras e merendeiras vêem os alunos e a satisfação deles em alimentarem-se como fatores positivos para a realização do controle de qualidade da alimentação escolar:

"O fator positivo é o sorriso das crianças em saber que tem uma merenda, porque a gente sabe que... Uma merenda de qualidade é uma merenda gostosa, saborosa... A gente sabe que muitas dessas crianças vêm sem comer nada porque não tem nada em casa e chegam aqui e encontram uma merenda. O fator positivo é que a gente não tem desperdício, não tem perdas, por que toda merenda que é feita ela é bem aceita pelos discentes" (GESTORA ESCOLA C).

"Com certeza os alunos né? Por que a gente vê que muitos alunos chegam aqui e não se alimentam [em casa] e aqui... Eu acho assim, que o que chega aqui é de qualidade e é preparado com qualidade" (MERENDEIRA ESCOLA C).

A gestora da escola A destaca ainda que:

"A boa vontade das pessoas envolvidas no processo [funcionários] ajuda a ter o controle de qualidade diante das dificuldades".

\section{Implicações da falta de controle de qualidade na recepção e no armazenamento dos alimentos}

O desperdício de alimentos na recepção e armazenamento constitui uma das consequências da falta de controle de qualidade nas UAE. A partir da análise dos registros e da observação em campo, foi possível identificar a perda de diversos gêneros alimentícios. Essas perdas foram ocasionadas pela presença de pragas (roedores e insetos, tais como os conhecidos como "gorgulho"), expiração do prazo de validade e deterioração:

" [...] Entregaram muito feijão. Pra você ter ideia, foram $125 \mathrm{~kg}$. E aqui, por ser abafado, pequeno e sem ventilação, esse feijão começou a dar gorgulho, mas eu notifiquei imediatamente à Secretaria quando eu percebi a existência de gorgulho. Foi afastada toda essa carga e foi devolvida à Secretaria Municipal de Educação. Eles vieram aqui, detectaram que a falha não foi nossa de armazenamento e sim pela quantidade que mandaram. Além da quantidade que mandaram, já mandaram uma mercadoria que não... Apesar de estar lá com prazo de validade extenso... O prazo de validade ainda ia vencer, mas deu gorgulho antes de vencer!" (GESTORA ESCOLA C).

"Às vežes estraga [os hortifrutigranjeiros]. Ai a gente tem que jogar fora!" (MERENDEIRA A).

Como estratégia para minimizar as perdas, gestoras e merendeiras adotavam medidas como: instalação de ventilador no depósito, elaboração e congelamento de polpas de alguns legumes e ajuste do cardápio planejado, o que, apesar de não solucionar o problema, reflete preocupação destes agentes com a alimentação escolar:

"[...] tivemos que mudar o cardápio semanal, antecipar e fazer a merenda com os gêneros que tinham ficado fora do freezer (GESTORA ESCOLA B).

" [...] Ai quando chegava muito e o freezer estava vazio, dava pra bater no liquidificador o tomate, batia as polpas de cebola, dava pra ajeitar e... Porque vinha muito tinha que fazer alguma coisa. Mas quando estava com o freezer cheio não tinha como fazer nada!" (MERENDEIRA ESCOLA B).

De acordo com Doró \& Santos [29], o desperdício de alimentos é um problema de particular importância quando se trata de programas de alimentação escolar, pois envolvem aspectos econômicos, sociais e até morais, e, portanto, técnicas apropriadas de controle de qualidade devem ser estudadas e suficientemente difundidas para evitar o desperdício. 
Outra implicação da falta do controle de qualidade dos alimentos nas escolas é o aumento do risco de Doenças Veiculadas por Alimentos (DVA). Este fato tem ainda um agravante considerando que $O$ público-alvo do PNAE, em sua grande maioria, são crianças, as quais fazem parte de um dos grupos de indivíduos mais vulneráveis a essas doenças ${ }^{[10]}$.

Segundo o Centro de Vigilância Epidemiológica de São Paulo, do total de surtos de DVA ocorridos no ano de 2003, 16,5\% aconteceram nas escolas e creches do Estado de São Paulo, devido, provavelmente, às práticas inadequadas de manipulação, matérias-primas contaminadas, falta de higiene durante a preparação, além de equipamentos e estrutura deficientes ${ }^{[27]}$.

Tanto o desperdício dos alimentos quanto as DVA resultam em prejuízos aos cofres públicos, e de nada adianta todo controle de qualidade realizado em nível central, na aquisição de produtos de boa procedência e a custos baixos, se não for garantida a qualidade nas etapas subsequentes da cadeia produtiva.

Diante dos principais problemas identificados nas escolas estudadas, constata-se a necessidade de medidas de intervenção por parte da EE, com vistas à garantia da qualidade dos alimentos e à promoção dos objetivos do PNAE. Dentre estas medidas destacamse: a ampliação do número de nutricionistas para compor o quadro técnico da SECULT; a adequação do número de funcionários das UAE e sua qualificação por meio de programas de formação continuada; melhoria da infraestrutura física das Unidades; mudança na logística de entrega dos gêneros alimentícios nas escolas e o desenvolvimento de parcerias com a Vigilância Sanitária local e com o CAE para realização de inspeções mais frequentes às UAE.

\section{CONCLUSÃO}

Todas as escolas apresentaram um nível de atendimento insatisfatório às legislações sanitárias, quanto ao controle de qualidade na recepção e no armazenamento dos alimentos, e os aspectos que mais contribuíram para o baixo nível de adequação global em todas as UAE foram os relativos à recepção dos alimentos e ao armazenamento dos hortifrutigranjeiros.

A deficiência da estrutura física das escolas, a insuficiência de equipamentos, a irregularidade na entrega dos gêneros, a não qualificação dos funcionários, e a falta de comprometimento de alguns gestores escolares - no monitoramento do prazo de validade dos produtos, no preenchimento do Mapa online e na supervisão das atividades dos funcionários, foram os principais fatores limitantes para a realização do controle de qualidade na recepção e no armazenamento dos alimentos.

Uma das principais implicações da falta de controle de qualidade de alimentos nas escolas foi o desperdício pela perda de gêneros.

Apesar de o presente trabalho se tratar de estudo de caso, seus resultados assemelham-se aos apontados em outros estudos, que também avaliaram escolas atendidas pelo PNAE e evidenciam a necessidade de medidas de intervenção, por parte daqueles que têm o poder decisório, de forma que os objetivos do PNAE sejam realmente promovidos nas escolas.

\section{AGRADECIMENTOS}

As autoras agradecem ao FNDE/PNAE pelo apoio financeiro na execução do projeto "Reorientação da operacionalização da alimentação escolar do município de Salvador e região metropolitana".

\section{REFERÊNCIAS}

[1] Brasil. Ministério da Educação. Fundo Nacional de Desenvolvimento da Educação. Alimentação escolar. Histórico [acesso em 26 nov 2009]. Disponível em: http://www.fnde.gov.br/index.php/ae-historico

[2] Brasil. Presidência da República. Lei no 11.947, de 16 de junho de 2009. Dispõe sobre o atendimento da alimentação escolar e do Programa Dinheiro Direto na Escola aos alunos da educação básica; altera as Leis 10.880, de 9 de junho de 2004, 11.273, de 6 de fevereiro de 2006, 11.507, de 20 de julho de 2007; revoga dispositivos da Medida Provisória no 2.178-36, de 24 de agosto de 2001, e a Lei no 8.913, de 12 de julho de 1994; e dá outras providências [acesso em 26 nov 2009]. Disponível em: http://www.fnde.gov.br/index.php/ae-legislacao

[3] Food and Agriculture Organization/World Health Organization. Food standards. Codex Alimentarius. Basic texts on food hygiene [acesso em 26 nov 2009]. Disponível em:

ftp://ftp.fao.org/codex/Publications/Booklets/Hygiene/FO odHygiene 2003e.pdf 
[4] Azevedo E. Educação, Saúde e Qualidade do Alimento [acesso em 26 nov 2009]. Disponível em: http://www.rebrae.com.br/artigo/artigo9.pdf

[5] Brasil. Ministério da Educação. Fundo Nacional de Desenvolvimento da Educação. Conselho Deliberativo. Resolução/CD/FNDE no 38, de 16 de julho de 2009. Dispõe sobre o atendimento da alimentação escolar aos alunos da educação básica no Programa Nacional de Alimentação Escolar - PNAE [acesso em 26 nov 2009]. Disponível em: http://www.fnde.gov.br/index.php/aelegislacao

[6] Conselho Federal de Nutricionistas. Resolução CFN no 358, de 18 de maio de 2005. Dispõe sobre as atribuições do Nutricionista no âmbito do Programa de Alimentação Escolar (PAE) e dá outras providências [acesso em 26 nov 2009]. Disponível em: http://www.fnde.gov.br/index.php/ae-legislacao

[7] Brasil. Ministério da Saúde. Agência Nacional de Vigilância Sanitária. Resolução da Diretoria Colegiada - RDC no 216, de 15 de setembro de 2004. Regulamento Técnico de Boas Práticas para Serviços de Alimentação. Diário Oficial da União, Brasília, 16 set. 2004. Seção 1, p. 25.

[8] Brasil. Ministério da Saúde. Portaria Interministerial no 1.010, de 8 de maio de 2006. Institui as diretrizes para a Promoção da Alimentação Saudável nas Escolas de educação infantil, fundamental e nível médio das redes públicas e privadas, em âmbito nacional. Diário Oficial da União, Brasília, 09 maio 2006. Seção 1, p. 70.

[9] Silva C, Germano MIS, Germano PML. Condições Higiênico-Sanitárias dos Locais de Preparação da Merenda Escolar, da Rede Estadual de Ensino em São Paulo, SP. Hig Aliment. 2003;17(110):49-55.

[10] Piragine KO. Aspectos higiênicos e sanitários do preparo da merenda escolar na rede estadual de ensino de Curitiba [dissertação]. Curitiba: Universidade Federal do Paraná; 2005.

[11] Farche LM, Pereira CHC, Castro GPP, Pelizer LH. O Panorama higiênico-sanitário nas cozinhas das escolas da rede pública de Franca, SP. Hig Aliment. 2007;21(154):27-29.

[12] Danelon MS, Silva MV. Análise das condições higiênico-sanitárias das áreas de preparo e consumo de alimentos, disponíveis para alunos de escolas públicas e privadas. Hig Aliment. 2007;21(152):25-30.

[13] Santos Filho FC, Santos FL, Silva MR, Curvelo FM, Rios JCC. Avaliação das condições higiênico-sanitárias de creches comunitárias da cidade de Salvador. Diálogos \& Ciências Revista da Rede de Ensino FTC [acesso em 26 nov 2009].
Disponível

em: http://dialogos.ftc.br/index.php?option $=$ com content\&task Eview\&id=172\&Itemid $=4$

[14] Cardoso RCV, Góes JAW, Almeida RCC, Guimarães AG, Barreto DL, Silva AS, et al. Programa Nacional de Alimentação Escolar (PNAE): Há Segurança na Produção da Alimentação em Escolas de Salvador (BA)? Rev Nutr. 2010;23(5):801-11.

[15] Salvador. Secretaria Municipal de Educação e Cultura. Educação em números [acesso em 26 nov 2009]. Disponível em: http://www.SECULT.salvador.ba.gov.br/site/educanumeros-escolas.php

[16] Brasil. Ministério da Saúde. Conselho Nacional de Saúde. Resolução CNS no 196, de 10 de outubro de 1996. Aprovar as diretrizes e normas regulamentadoras de pesquisas envolvendo seres humanos [acesso em 26 nov 2009]. Disponível em: http://conselho.saude.gov.br/docs/Resolucoes/Reso196.do c

[17] Brasil. Ministério da Saúde. Agência Nacional de Vigilância Sanitária. Resolução da Diretoria Colegiada - RDC no 275 , de 21 de outubro de 2002. Dispõe sobre o Regulamento Técnico de Procedimentos Operacionais Padronizados aplicados aos Estabelecimentos Produtores/Industrializadores de Alimentos e a Lista de Verificação das Boas Práticas de Fabricação em Estabelecimentos Produtores/Industrializadores de Alimentos. Diário Oficial da União, Brasília, 22 out. 2002. Seção 1, p. 126.

[18] Brasil. Ministério da saúde. Agência Nacional de Vigilância Sanitária. Alimentos. Orientações ao consumidor de alimentos [acesso em 29 nov 2009]. Disponível em: http://www.anvisa.gov.br/ALIMENTOS/consumidor/rote iro.htm

[19] Serviço Nacional de Aprendizagem Comercial. Cartilha 3: as boas práticas, II. 2 ${ }^{\text {a }}$ ed. Rio de janeiro: Senac Nacional, 2005. 24 p. (Qualidade e Segurança Alimentar). Programa Alimentos Seguros - Mesa. Convênio PAS Integrado. CNC/CNI/SENAI/SESI/SEBRAE/SESC/SENAC/AN VISA.

[20] Guimarães KAS, Silva FFL, Carvalho MS, Vasconcelos FA. Monitoramento das conformidades no recebimento de gêneros alimentícios, numa unidade de alimentação e nutrição na cidade do Rio de Janeiro. Hig Aliment. 2007;21 (156):18-23.

[21] Manual Aberc de Práticas de Elaboração e Serviço de Refeições para Coletividades. 8aㅗ ed. São Paulo: ABERC, 2003. 
[22] Manual do responsável técnico. Rio de Janeiro: SENAC/DN, 2001. 120 p. (Qualidade e Segurança Alimentar). Projeto APPCC Mesa. Convênio CNC/CNI/SEBRAE/ANVISA.

[23] Riedel, G. Estocagem de alimentos e combate a Insetos e Roedores. In: Riedel, G. Controle Sanitário dos Alimentos. 3a ed. São Paulo: Atheneu; 1992. p. 389-404.

[24] Serviço Nacional de Aprendizagem Comercial. Cartilha 5: passo a passo para implantação de boas práticas e sistema APPCC. Série qualidade e segurança alimentar. Rio de janeiro: Senac Nacional, 2005. 24 p. (Qualidade e Segurança Alimentar). Programa Alimentos Seguros - Mesa. Convênio PAS Integrado. CNC/CNI/SENAI/SESI/SEBRAE/SESC/SENAC/AN VISA.

[25] Pistore AR, Gelinskib JMLN. Avaliação dos conhecimentos higiênico-sanitários de manipuladores de merenda escolar: fundamento para treinamento contínuo e adequado. Hig Aliment. 2006;20(146):17-20.

[26] Brasil. Ministério da Saúde. Secretaria de Atenção à Saúde. Departamento de Atenção Básica. Manual operacional para profissionais de saúde e educação: promoção da alimentação saudável nas escolas/Ministério da Saúde,
Secretaria de Atenção à Saúde, Departamento de Atenção Básica. Brasilia: Ministério da Saúde, 2008. 152 p. (Série A. Normas e Manuais Técnicos) [acesso em 26 Nov 2009]. Disponível em: http://bvsms.saude.gov.br/bvs/publicacoes/promocao ali mentacao saudavel escolas.pdf

[27] Costa EQ, Lima ES, Ribeiro, VMB. O treinamento de merendeiras: análise do material instrucional do Instituto de Nutrição Annes Dias. Rio de Janeiro (1956-94). Hist Cienc Saúde - Manguinhos. 2002;9(3):535-60.

[28] Salvador. Secretaria Municipal de Educação e Cultura. Educação dever de todos: atribuições dos gestores escolares da rede pública municipal de ensino. Versão preliminar [Internet]. Salvador: SECULT, 2003 [acesso em 26 nov 2009]. Disponível em: http://www.SECULT.salvador.ba.gov.br/documentos/atrib uicoes-dos-gestores-escolares.pdf

[29] Doró CT, Santos CMC. Modelo simplificado de controle de qualidade da alimentação escolar. Em Aberto. Brasília, 1995 [acesso em 26 nov 2009]. Disponível em: http://www.emaberto.inep.gov.br/index.php/emaberto/arti cle/viewFile/1019/921 